\title{
Genetic variation and population structure of clonal Zingiber zerumbet at a fine geographic scale: a comparison with two closely related selfing and outcrossing Zingiber species
}

Rong Huang ${ }^{1 \dagger}$, Yu Wang ${ }^{1 \dagger},{\text { Kuan } \mathrm{Li}^{1} \text { and Ying-Qiang Wang }}^{1,2^{*}}$ (])

\begin{abstract}
Background: There has always been controversy over whether clonal plants have lower genetic diversity than plants that reproduce sexually. These conflicts could be attributed to the fact that few studies have taken into account the mating system of sexually reproducing plants and their phylogenetic distance. Moreover, most clonal plants in these previous studies regularly produce sexual progeny. Here, we describe a study examining the levels of genetic diversity and differentiation within and between local populations of fully clonal Zingiber zerumbet at a microgeographical scale and compare the results with data for the closely related selfing Z. corallinum and outcrossing Z. nudicarpum. Such studies could disentangle the phylogenetic and sexually reproducing effect on genetic variation of clonal plants, and thus contribute to an improved understanding in the clonally reproducing effects on genetic diversity and population structure.

Results: The results revealed that the level of local population genetic diversity of clonal Z. zerumbet was comparable to that of outcrossing Z. nudicarpum and significantly higher than that of selfing Z. corallinum. However, the level of microgeographic genetic diversity of clonal Z. zerumbet is comparable to that of selfing $Z$. corallinum and even slightly higher than that of outcrossing Z. nudicarpum. The genetic differentiation among local populations of clonal $Z$. zerumbet was significantly lower than that of selfing $Z$. corallinum, but higher than that of outcrossing $Z$. nudicarpum. A stronger spatial genetic structure appeared within local populations of Z. zerumbet compared with selfing Z. corallinum and outcrossing Z. nudicarpum.

Conclusions: Our study shows that fully clonal plants are able not only to maintain a high level of within-population genetic diversity like outcrossing plants, but can also maintain a high level of microgeographic genetic diversity like selfing plant species, probably due to the accumulation of somatic mutations and absence of a capacity for sexual reproduction. We suggest that conservation strategies for the genetic diversity of clonal and selfing plant species should be focused on the protection of all habitat types, especially fragments within ecosystems, while maintenance of large populations is a key to enhance the genetic diversity of outcrossing species.
\end{abstract}

Keywords: Reproduction mode, Genetic differentiation, Spatial genetic structure, Zingiber zerumbet

\footnotetext{
*Correspondence: wangyq@scnu.edu.cn

${ }^{\dagger}$ Rong Huang and Yu Wang contributed equally to this work

${ }^{1}$ Guangzhou Key Laboratory of Subtropical Biodiversity

and Biomonitoring, School of Life Sciences, South China Normal

University, Guangzhou 510631, China

Full list of author information is available at the end of the article
}

\begin{abstract}
Background
For most vascular plant species, there are two distinct modes of reproduction: sexual and asexual, through vegetative reproduction and apomixis $[1,2]$. For plants
\end{abstract}


reproducing asexually, vegetative reproduction is extremely common in perennial plants $[1,3]$. The two modes of reproduction are accompanied by contrasting genetic consequences $[2,4,5]$. Understanding the effects on genetic diversity of the means of reproduction used by plants could provide significant insights into their evolutionary biology and conservation, and thus this has attracted extensive concern and research interest [6].

Plants that employ sexual reproduction can achieve gene exchange between individuals and populations via pollen and seed, while plants relying solely on vegetative reproduction are generally not readily dispersed far from the parent plant [4, 7-9]. Thus, for plants reproducing sexually, there is opportunity for the addition of new genotypes via gene flow and/or genetic recombination [10]. For plants reproducing asexually, in contrast, it is predicted that genetic variation will reduce as a result of the absence of segregation and genetic recombination [11-13], as evidenced by various studies on genetic variation in clonal plants $[14,15]$. In contrast to the theoretical predictions, many empirical studies on genetic variation of clonal plants, however, have shown that their population genetic diversity, on average, is generally similar to, or even higher than that of sexually reproducing plants $[11,16-20]$. This has led to the widely accepted idea that average genetic variation in populations of clonal plants generally appears as diverse as that of non-clonal plants $[18,21,22]$. In fact, the maintenance of within-population genetic diversity of clonally reproducing species should take into account several facts, e.g. the recruitment of new genotypes through sexually produced diaspores, diversifying selection in different environmental conditions and somatic mutation $[11,16,17]$. The most common reason behind a high level of genetic diversity in populations of many clonal plants with a capacity for sexual reproduction is the sporadic and limited episodes of sexual reproduction $[13,18,23-30]$. For example, asexually reproducing populations of the shrub Acacia carneorum contained multiple genets, which can be attributed to occasional sexual recruitment [13], and perennial clonal herbaceous Maianthemum bifolium showed high genotypic diversity resulting from very limited sexual recruitment [18]. However, these previous studies did not take into account the mating system of the non-clonal plants concerned, which is the most important factor affecting genetic diversity and spatial genetic structure of populations within species [31-33]; that is, a comparison was not made with selfing and outcrossing plants. For example, Meloni et al. [34] did not consider the breeding system when comparing the genetic diversity of clonal species and sexually reproducing species in the Canary Islands. Moreover, it is worth noting that most clonal plants in these previous studies regularly produce sexual progeny. Numerous studies on genetic variation have shown that, compared to outcrossing plants, self-fertilizing plants have less genetic diversity at both the population and species levels, but genetic differentiation among populations is strengthened $[35,36]$. Therefore, given the influences of mating system on genetic diversity, it can be difficult to fully understand the impact of clonal reproduction on genetic variation and spatial genetic structure of populations of clonal plants regularly producing sexual progeny, because its roots lie in a complex mixture of factors. Undoubtedly, studies comparing obligatory clonal plants with selfing and outcrossing plants are needed and could contribute to an improved understanding of the effect of clonal reproduction on population genetic diversity and spatial genetic structure of plants. In addition, the value of previous studies for analysis of clonal reproduction effects on genetic diversity is reduced by lack of consideration of phylogeny. Phylogenetic relationships between the species in focus may confound the comparative analyses of genetic diversity between unrelated asexual and sexual plant species [31,37], as phylogenetically related species may exhibit combinations of character values that are inherited to some degree from a common ancestor [38]. Given this, comparative studies of closely related taxa have the advantage of being able to better isolate the effects of variation in single traits (e. g. modes of reproduction) on genetic structure [31]. Therefore, comparative studies on population genetic structure between closely related obligatory clonal plant species and sexual plant species can disentangle the phylogenetic effect on genetic variation.

In this study, we focus on a fully clonal plant species from China, Zingiber zerumbet (L.) Smith, which is a perennial herb species of section Zingiber of the genus Zingiber, closely related to selfing $Z$. corallinum and outcrossing Z. nudicarpum (Additional file 1: Fig. S1) [39, 40]. All of the three Zingiber plants are highly ornamental and can be used medicinally [39-42]. Our previous studies comparing the genetic structure of the two closely related selfing and outcrossing Zingiber species at landscape level [43] and fine scale level [44] have shown that selfing $Z$. corallinum can maintain a high level of genetic diversity at both geographic scales, similar to that of outcrossing $Z$. nudicarpum, albeit with low genetic diversity within populations or subpopulations. Here, therefore, we assess the levels of genetic variation and differentiation within and among local populations of fully clonal Zingiber zerumbet at a microgeographic scale using ISSR markers, and compare the results with those for the two closely related species, selfing $Z$. corallinum and outcrossing $Z$. nudicarpum. The genetic variation and structure of plant populations can reveal useful information about, and is regarded as the strategic mainstay 
of, biodiversity and the diversity of a species within and among wild populations inhabiting an ecosystem $[45,46]$. Thus, an increased understanding of genetic diversity and genetic structure in species found in habitats is key to the development of conservation strategies for small and isolated populations $[47,48]$. In this study, we focus on the following questions. (1) Is the genetic diversity lower in clonal Zingiber species than in selfing and outcrossing Zingiber, as theory predicts? (2) Are there differences

Table 1 Attributes of ISSR primers of Zingiber zerumbet used in the present study

\begin{tabular}{llllll}
\hline Primer & Sequence $\mathbf{5}^{\prime}$ to $\mathbf{3}^{\prime}$ & $\mathbf{T m}\left({ }^{\circ} \mathbf{C}\right)$ & SR $(\mathbf{b p})$ & NT & NP \\
\hline 810 & $(\mathrm{GA}) 8 \mathrm{~T}$ & 44 & $220-2350$ & 22 & 13 \\
811 & $(\mathrm{GA}) 8 \mathrm{~T}$ & 52 & $230-2050$ & 22 & 20 \\
817 & $(\mathrm{CA}) 8 \mathrm{~A}$ & 56 & $270-1750$ & 21 & 20 \\
826 & $(\mathrm{AC}) 8 \mathrm{C}$ & 56 & $230-1800$ & 27 & 21 \\
834 & $(\mathrm{AG}) 8 \mathrm{Y}^{*} \mathrm{~T}$ & 46 & $320-2100$ & 23 & 23 \\
841 & $(\mathrm{GA}) 8 \mathrm{Y}^{*} \mathrm{C}$ & 56 & $180-1850$ & 24 & 24 \\
847 & $(\mathrm{CA}) 8 \mathrm{R}^{*} \mathrm{C}$ & 59 & $180-2200$ & 38 & 35 \\
857 & $(\mathrm{AC}) 8 Y^{*} \mathrm{G}$ & 48.5 & $180-1950$ & 24 & 19 \\
884 & $\mathrm{HBH}(\mathrm{AG}) 7$ & 52.5 & $220-1850$ & 23 & 20 \\
887 & $\mathrm{DVD}^{*}(\mathrm{TC}) 7$ & 52 & $370-1950$ & 22 & 20 \\
888 & $\mathrm{BDB}^{*}(\mathrm{CA}) 7$ & 56 & $270-2050$ & 21 & 13 \\
889 & $\mathrm{DBD}^{*}(\mathrm{AC}) 7$ & 59 & $270-1850$ & 26 & 22 \\
Total & - & - & $180-2350$ & 293 & 250 \\
\hline
\end{tabular}

* $B=(C, G, T), D=(A, G, T), R=(A, T), V=(A, C, G), Y=(C, G), H=(A, C, T)$

Tm annealing temperature, $S R$ size range of amplified fragments, $N T$ total number of bands, NP number of polymorphic bands in the spatial genetic structure among Zingiber populations at microgeographic scales related to mode of reproduction?

\section{Results}

ISSR polymorphism, genetic diversity and clonal diversity The ISSR polymorphism, genetic diversity and clonal diversity data are summarized in Tables 1 and 2. The primers produced 293 reliable ISSR bands from four local populations of $Z$. zerumbet across Dongshui Mountain, of which $250(85.32 \%)$ were polymorphic, there were 38 specific bands (12.97\%). At the microgeographic level, the values of Nei's gene diversity $(h)$ and Shannon's genetic diversity index $(I)$ were 0.2409 and 0.3713 , respectively. At the local population level, the values of $h$ and $I$ ranged from 0.1140 to 0.1971 (average 0.1448) and from 0.1695 to 0.2955 (average 0.2157 ), respectively. The 12 selected primers identified 205 genotypes from 229 individuals, and $199(86.9 \%)$ of those were unique. The number of genotypes $(G)$ per local population ranged from 24 at MLH to 105 at HJC (average 51.3), and the number of unique genotypes ranged from 24 at MLH and DS1 to 104 at HJC (average 49.8). Simpson's diversity index $(D)$ was 1.00 for all individuals at microgeographic level, and ranged from 0.90 to 1.00 (average 0.97 ) at local population level.

The patterns of allele frequency are shown in Fig. 1. Among all local populations except HJC, common loci (i.e. found in all individuals within local populations: allele frequency $=100 \%$ ) accounted for the highest proportion $(49.78 \%-55.19 \%)$ of amplified

Table 2 Comparison of genetic diversity and clonal diversity parameters based on ISSR for local populations of Zingiber zerumbet at the microgeographic scale with that of selfing $Z$. corallinum and outcrossing $Z$. nudicarpum. (The data of $Z$. corallinum and $Z$. nudicarpum utilized in this study are from Huang et al. [44].)

\begin{tabular}{|c|c|c|c|c|c|c|c|c|c|c|c|c|}
\hline Local population & Sample size & $G$ & $S$ & $G / N$ & $D$ & $P L$ & PPL (\%) & $\mathrm{Na}$ & $\mathrm{Ne}$ & $h$ & $I$ & NS \\
\hline \multicolumn{13}{|l|}{ Z. zerumbet } \\
\hline DS1 & 45 & 26 & 24 & 0.58 & 0.90 & 95 & 32.42 & 1.3242 & 1.1972 & 0.1140 & 0.1695 & 7 \\
\hline DS2 & 54 & 50 & 47 & 0.93 & 0.99 & 116 & 39.59 & 1.3959 & 1.2258 & 0.1342 & 0.2024 & 5 \\
\hline MLH & 24 & 24 & 24 & 1.00 & 1.00 & 102 & 34.81 & 1.3481 & 1.2402 & 0.1340 & 0.1955 & 5 \\
\hline $\mathrm{HJC}$ & 106 & 105 & 104 & 0.99 & 1.00 & 174 & 59.39 & 1.5653 & 1.3399 & 0.1971 & 0.2955 & 21 \\
\hline Average & 57 & 51.3 & 49.8 & 0.90 & 0.97 & 122 & 41.55 & 1.4084 & 1.2508 & 0.1448 & 0.2157 & 9.5 \\
\hline Total & 229 & 205 & 199 & 0.90 & 1.00 & 250 & 85.32 & 1.8532 & 1.3952 & 0.2409 & 0.3713 & 38 \\
\hline \multicolumn{13}{|l|}{ Z. corallinum } \\
\hline Average & 33 & & & & & 38 & 20.30 & 1.2028 & 1.1129 & 0.0662 & 0.0995 & 11.3 \\
\hline Total & 115 & & & & & 157 & 84.20 & 1.7655 & 1.4245 & 0.2490 & 0.3753 & 39.5 \\
\hline \multicolumn{13}{|l|}{ Z. nudicarpum } \\
\hline Average & 34 & & & & & 119 & 52.60 & 1.5256 & 1.2421 & 0.1464 & 0.2257 & 5 \\
\hline Total & 86 & & & & & 194 & 83.80 & 1.8384 & 1.3768 & 0.2246 & 0.3480 & 12.5 \\
\hline
\end{tabular}

$G$ number of genotypes, $S$ number of genotypes found only once, $G / N$ the number of genotypes (G) relative to that of samples (N), $D$ Simpson's diversity index, $P L$ number of polymorphic loci, PPL percentage of polymorphic loci, Na number of observed alleles, Ne number of effective alleles, $h$ Nei's gene diversity, I Shannon's information index, NS number of specific bands 


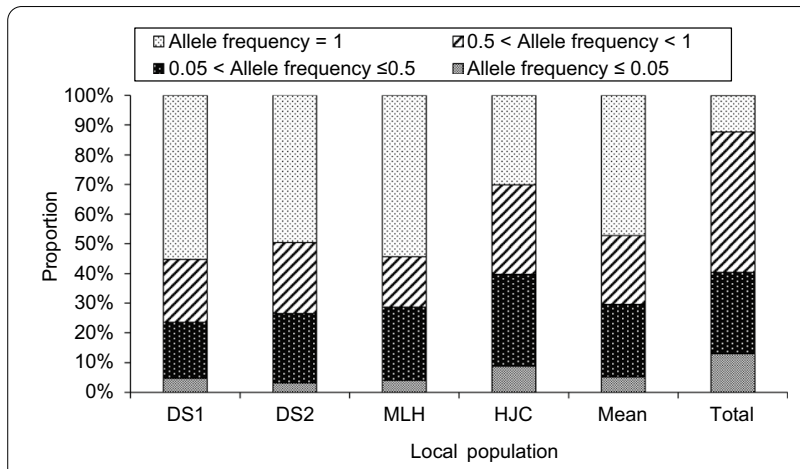

Fig. 1 Distribution of allele frequency in local populations of Zingiber zerumbet within the microgeographic area

fragments, followed by low-medium allele frequency loci $(5 \%<$ allele frequency $\leq 50 \%) \quad(18.87 \%-24.66 \%)$ and medium-high allele frequency loci $(50 \%<$ allele frequency $<100 \%)(17.04 \%-23.81 \%)$. However, common loci, medium-high allele frequency loci and lowmedium allele frequency loci accounted for a similar proportion of amplified fragments in HJC, i.e. $30.12 \%$ and $30.12 \%$ and $30.92 \%$, respectively. Rare loci (allele frequency $\leq 5 \%$ ) accounted for the lowest proportion $(3.14 \%-8.84 \%)$ of amplified fragments in all four subpopulations. At the microgeographic level, both common loci (i.e. found in all local populations within the microgeographic area: allele frequency $=100 \%$ ) and rare loci were less prevalent, i.e. $12.32 \%$ and $13.03 \%$, respectively. However, medium-high allele frequency loci accounted for the highest proportion (47.18\%) of amplified fragments, followed by the low-medium allele frequency loci (27.46\%).

\section{Genetic differentiation and gene flow at the microgeographic scale}

The genetic differentiation statistics for all subpopulations are presented in Table 3. The Nei's $G_{\mathrm{ST}}$ values for the local populations of $Z$. zerumbet at the microgeographic scale were estimated as 0.4008 , which indicates that $59.92 \%$ of the genetic variability was distributed within local populations. The estimate of gene flow $(\mathrm{Nm})$ per generation among the local populations was 0.7476 . The AMOVA analysis was consistent with the Nei's genetic differentiation statistics, showing that $46.0 \%\left(\Phi_{\mathrm{ST}}=0.460\right)$ of the total variation was partitioned among local populations of $Z$. zerumbet at the microgeographic scale (Table 4). That is, of the total molecular variance, $54.0 \%$ was attributable to individual differences in Z. zerumbet.
Table 3 Comparison of genetic differentiation statistics between local populations of clonal Zingiber zerumbet at the microgeographic scale with that of selfing $Z$. corallinum and outcrossing $Z$. nudicarpum. (The data of $Z$. corallinum and $Z$. nudicarpum utilized in this study are from Huang et al. [44].)

\begin{tabular}{lllll}
\hline Local populations & $\boldsymbol{H}_{\mathbf{T}}$ & $\boldsymbol{H}_{\mathbf{S}}$ & $\boldsymbol{G}_{\mathbf{S T}}$ & $\boldsymbol{N}$ \\
\hline Z. zerumbet & & & & \\
DS1 vs MLH & 0.1815 & 0.1242 & 0.3158 & 1.0831 \\
DS1 vs DS2 & 0.1892 & 0.1243 & 0.3427 & 0.9588 \\
DS1 vs HJC & 0.2312 & 0.1557 & 0.3264 & 1.0319 \\
MLH vs DS2 & 0.1701 & 0.1341 & 0.2117 & 1.8623 \\
MLH vs HJC & 0.2178 & 0.1655 & 0.2401 & 1.5823 \\
DS2 vs HJC & 0.2197 & 0.1657 & 0.2459 & 1.5337 \\
Average & 0.2016 & 0.1449 & 0.2804 & 1.3420 \\
Total & 0.2299 & 0.1405 & 0.4008 & 0.7476 \\
Z. corallinum & & & & \\
Average & 0.1920 & 0.0622 & 0.6782 & 0.3060 \\
Total & 0.2484 & 0.0721 & 0.7110 & 0.2575 \\
Z. nudicarpum & & & & \\
Average & 0.2013 & 0.1449 & 0.2680 & 1.6596 \\
Total & 0.2269 & 0.1474 & 0.3408 & 1.0311 \\
\hline
\end{tabular}

$H_{\mathrm{T}}$ total microgeographic diversity, $H_{\mathrm{S}}$ average within local population diversity, $G_{\mathrm{ST}}$ local population differentiation, $\mathrm{Nm}$ gene flow

\section{Genetic structure and cluster analysis at the microgeographic scale}

Bayesian genetic analyses performed with STRUCTURE revealed that with the log likelihood reached its maximum value at $K=2$, when all individuals from four local populations of $Z$. zerumbet could be assigned to two genetic clusters (Fig. 2). Except for population MLH, almost all individuals within each local population were assigned to the same genetic clusters. The local populations DS1, DS2 and MLH were assigned to the same cluster and HJC was assigned to a second cluster. In MLH, there was a high degree of admixing of two gene pools.

The UPGMA dendrogram (Fig. 3a) based on the Dice coefficient was broadly consistent with the unrooted neighbor-joining (NJ) tree (Fig. 3b) based on Nei's genetic distance in local populations of $Z$. zerumbet at the microgeographic scale. All individuals from the same local populations were clustered together with the exception of three individuals from MLH when using an arithmetic average analysis. The 229 individuals were first grouped into two clusters (I, II) and then cluster I formed three further well-resolved clades (A, B and C) comprising all individuals from local populations DS1, MLH and DS2, respectively (Fig. 3). Cluster II consisted of clade D only, which comprised all individuals from HJC. Except for seven individuals, all the neighboring individuals within local populations clustered together (Fig. 3a, b). The PCoA broadly confirmed the partitioning results of 
Table 4 Comparison of summary of analysis of molecular variance (AMOVA) for local populations of clonal Zingiber zerumbet at the microgeographic scale with that of selfing Z. corallinum and outcrossing Z. nudicarpum. (The data of Z. corallinum and Z. nudicarpum utilized in this study are from Huang et al. [44])

\begin{tabular}{|c|c|c|c|c|c|c|c|c|}
\hline Subpopulation & Source & df & Sums of squares & Mean squares & $\begin{array}{l}\text { Variance } \\
\text { component }\end{array}$ & $\begin{array}{l}\text { Percentage of } \\
\text { variation (\%) }\end{array}$ & $\Phi_{\mathrm{ST}}$ & $p$ \\
\hline \multicolumn{9}{|l|}{ Z.zerumbet } \\
\hline & Between local populations & 3 & 2647.505 & 882.502 & 16.613 & 46.0 & 0.460 & 0.001 \\
\hline & Within local populations & 225 & 4387.936 & 19.502 & 19.502 & 54.0 & & \\
\hline \multicolumn{9}{|l|}{ Z. corallinum } \\
\hline & Between local populations & 6 & & & 23.942 & 78.4 & 0.784 & 0.001 \\
\hline & Within local populations & 224 & & & 12.152 & 21.6 & & \\
\hline \multicolumn{9}{|l|}{ Z. nudicarpum } \\
\hline & Between local populations & 4 & & & 19.451 & 46.8 & 0.468 & 0.001 \\
\hline & Within local populations & 168 & & & 17.172 & 53.2 & & \\
\hline
\end{tabular}

$d f$ degrees of freedom, $\Phi_{\mathrm{ST}}$ between local populations deviations from Hardy-Weinberg expectations, $p$ the probability of accepting the null hypothesis

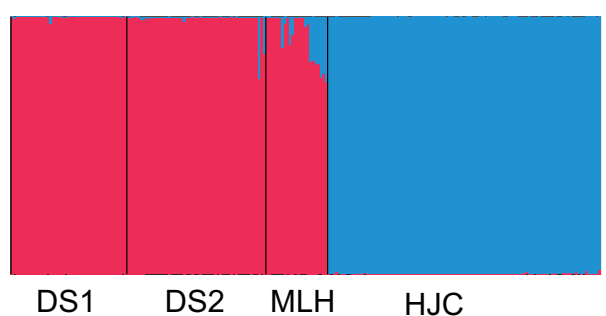

Fig. 2 Genetic-group-structure shown by STRUCTURE analysis for local populations of Zingiber zerumbet within the microgeographic area. Each individual vertical bar represents an individual and the black vertical bars separate the local populations, while different colors represent different gene pools

the UPGMA and NJ clustering (Fig. 4b). The Mantel Test revealed that there was no significant isolation-by-distance relationship across local populations of $Z$. zerumbet at the microgeographic scale $(\mathrm{r}=0.420, p=0.297)$ (Fig. 5).

The spatial autocorrelation analysis indicated that significant positive spatial genetic structure was detected at $2-14 \mathrm{~m}(r=0.268 \pm 0.125, p<0.05)$ within local populations of Z. zerumbet (Fig. 6).

\section{Discussion}

Is the genetic diversity of a clonal Zingiber species lower or higher than that of sexual Zingiber species?

Genetic uniformity could be expected within populations of strictly clonal species [25]. Contrary to theoretical predictions, some comparative studies on genetic variation between unrelated clonal and sexual plants species have shown that the genetic variation of the former is comparable to that of the latter $[18,21,22]$. Nevertheless, there are a few studies comparing genetic diversity in populations between closely related clonal plants and non-clonal or less clonal ones (e. g. Typha angustifolia and T. latifolia [49]; Gagea lutea and G. spathacea [50]), showing lower levels of genetic diversity in populations of clonal plants. The present study revealed that the level of local population genetic diversity in clonal $Z$. zerumbet was comparable to that in closely related outcrossing $Z$. nudicarpum (h: 0.1448 vs $0.1464, p=0.95 ; I: 0.2157$ vs 0.2257 , $p=0.79)$ and significantly higher than that in closely related selfing $Z$. corallinum ( $h$ : 0.1448 vs $0.0662, p=0.05$; I: 0.2157 vs $0.0995, p=0.05)$. However, the level of microgeographic genetic diversity of clonal $Z$. zerumbet is comparable to that of selfing $Z$. corallinum ( $h: 0.2409$ vs $0.2490, p=0.587 ; I: 0.3713$ vs $0.3753, p=0.838$ ), and even slightly higher than that of outcrossing $Z$. nudicarpum (h: 0.2409 vs $0.2246, p=0.389 ; I: 0.3713$ vs 0.3480 , $p=0.493)$. These results suggest that, compared with outcrossing $Z$. nudicarpum, the genetic diversity of local populations of clonal $Z$. zerumbet at the microgeographic scale will be less affected by reduced gene flow because each individual contains most of the genetic variation within the population, similar to selfing $Z$. corallinum [44]. In addition, the clonal diversity of $Z$. zerumbet at the microgeographic scale was also relatively high, with most of the sampled plants representing unique genotypes (199 genets out of 229 sampled). The observed values of clonal diversity of $Z$. zerumbet $(G / N=0.90 ; D=0.97)$ were higher than the average values of clonal plant species in several literature surveys (e.g. $G / N=0.17, D=0.67$ for 21 clonal species summarized by Ellstrand and Roose [16]; $G / N=0.27 ; D=0.75$ for 45 clonal species reported by Widén et al. [17]; $G / N=0.44 ; D=0.85$ for 77 clonal species reported by Honnay and Jacquemyn [19]). This may be because these previous reviews of clonal diversity included taxa with various levels of sexual reproduction. It indicates that obligatory clonal plant species may have 


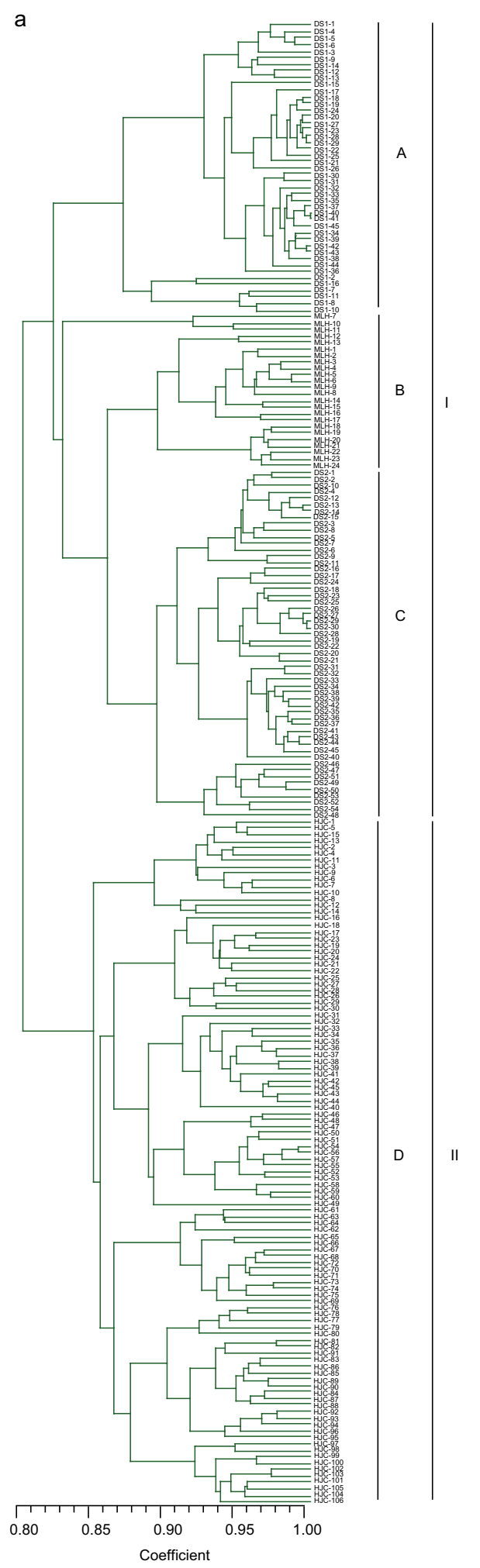

b

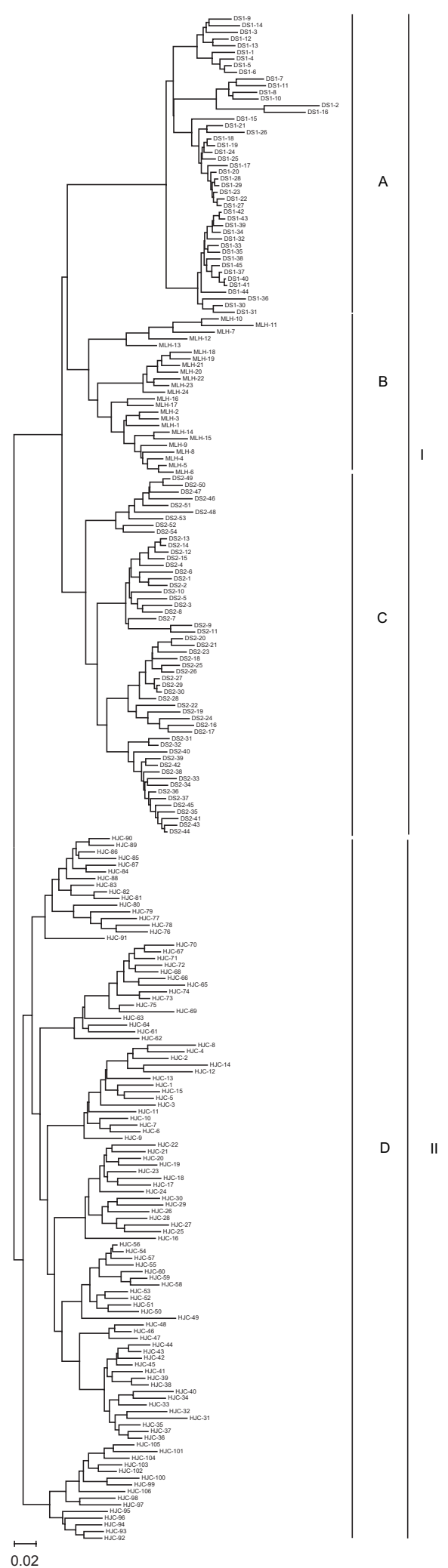

Fig. 3 UPGMA dendrogram a based on the Dice coefficient and an unrooted Neighbor-Joining tree, $\mathbf{b}$ based on Nei's genetic distance for individuals in local populations of Zingiber zerumbet within the microgeographic area 

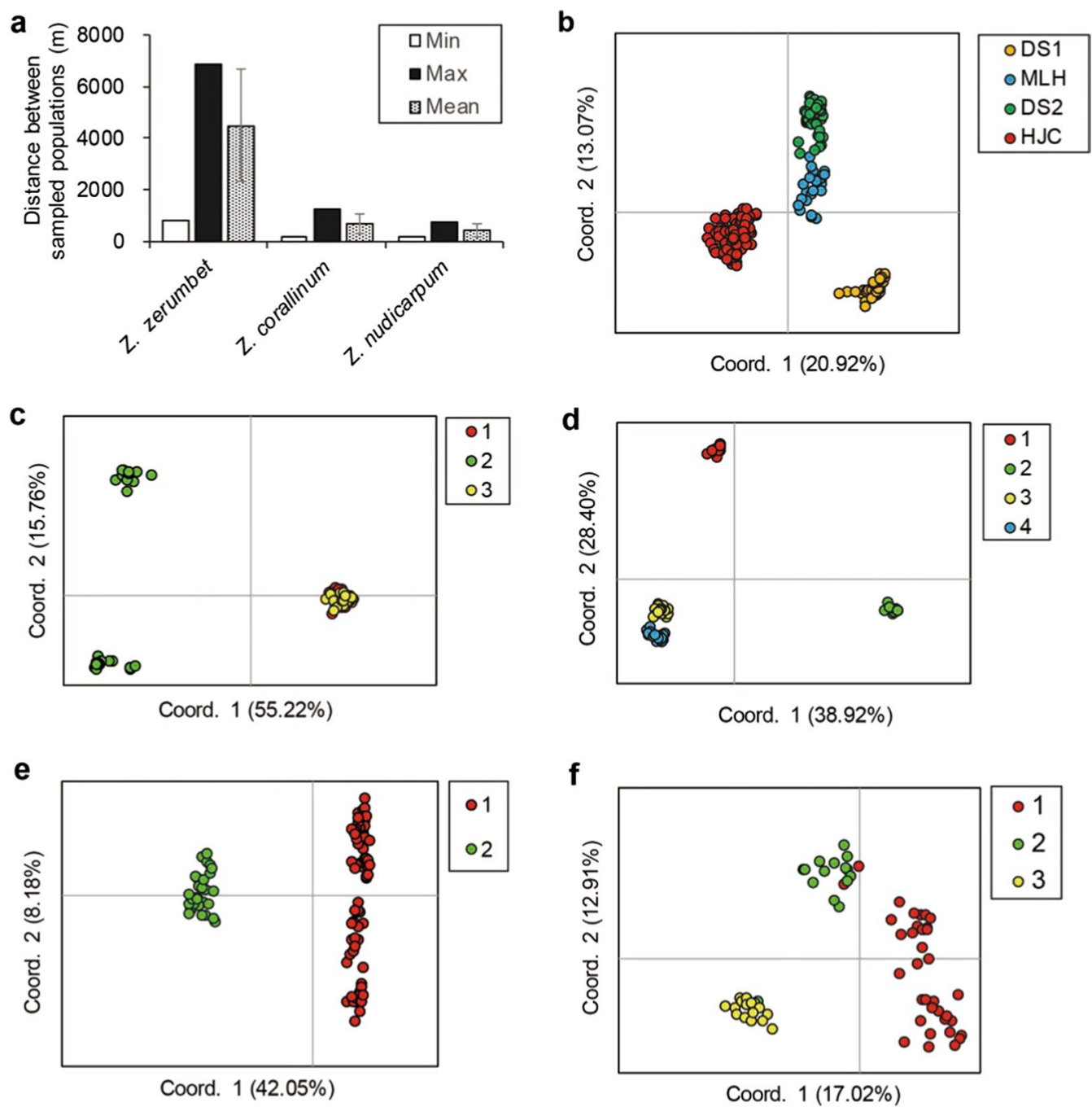

Fig. 4 Comparison of scatterplot of the principal coordinate analysis (PCOA) based on ISSR polymorphisms for individuals in local populations of clonal Zingiber zerumbet within the microgeographic area with that of selfing Z. corallinum and outcrossing Z. nudicarpum. Different colors represent individuals from different local populations. (a minimum, maximum, and mean distance between sampled populations of the three Zingiber species, $\mathbf{b}$ Z. zerumbet, $\mathbf{c}, \mathbf{d} Z$. corallinum, e, $\mathbf{f} Z$. nudicarpum; the figures of $Z$. corallinum and $Z$. nudicarpum utilized in this study are from Huang et al. [44])

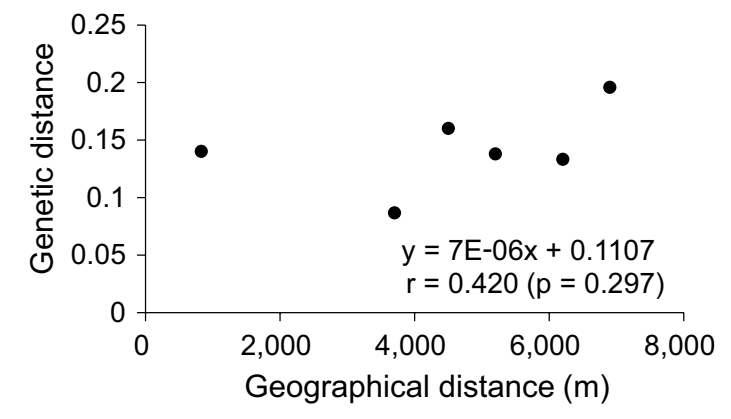

Fig. 5 Correlation between geographic distance and Nei's genetic distance between local populations of Zingiber zerumbet within the microgeographic area higher clonal diversity than other clonal species with various levels of sexual reproduction. We suggest that fully clonal plant species (such as Z zerumbet) are able not only to maintain a high level of within-population genetic diversity as outcrossing plant species (such as $Z$. nudicarpum), but can also harbor as high a level of microgeographic genetic diversity as selfing plant species (such as $Z$. corallinum), albeit by adopting diverse strategies.

Unlike outcrossing plant species, obligatory clonal plant species, like selfing ones, cannot maintain high genetic diversity within/among populations through frequent exchange of genes [51]. However, without migration among demes of local populations 


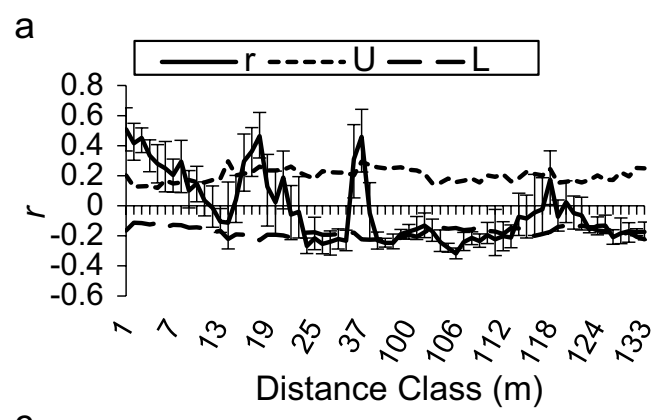

C
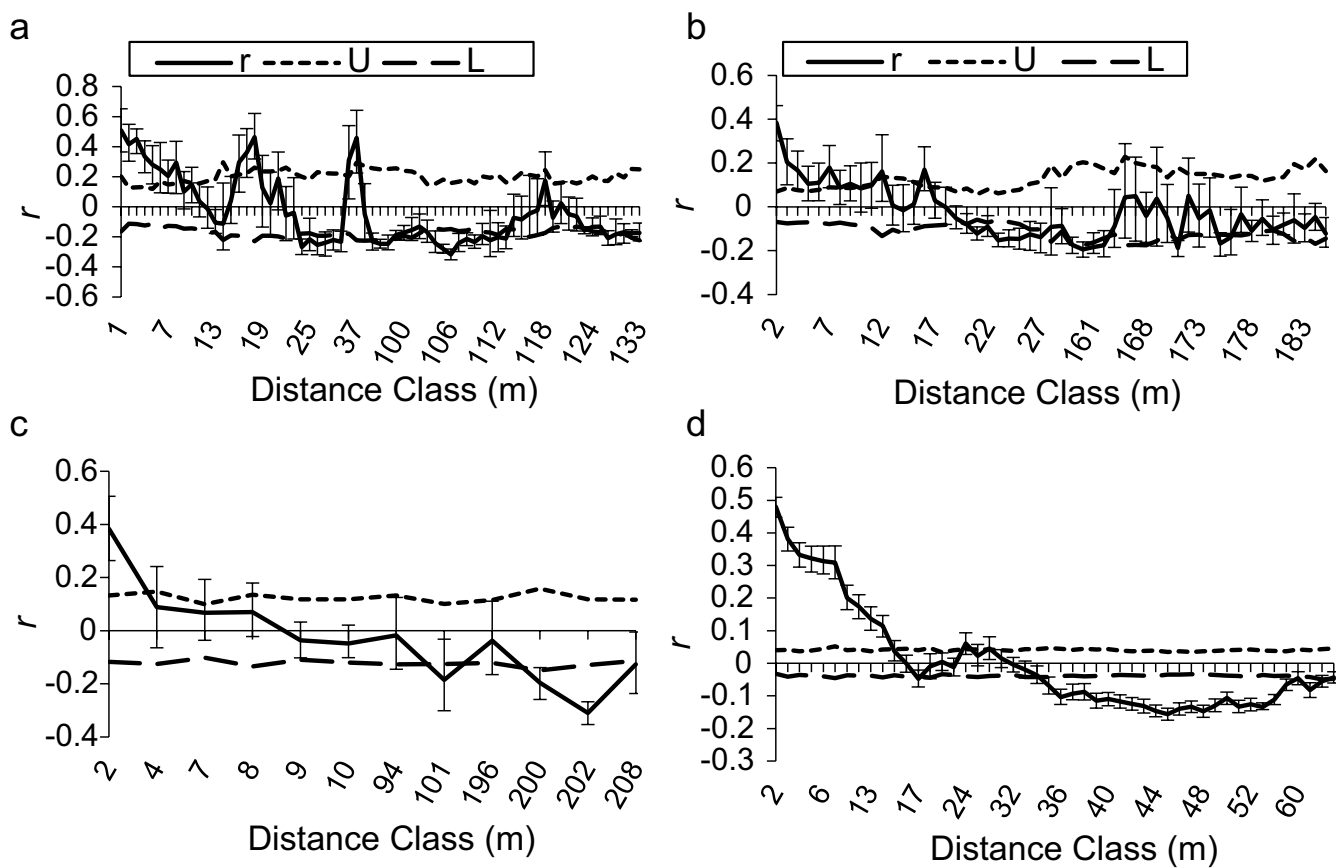

Fig. 6 Correlogram showing the spatial autocorrelation coefficient ( $r$ ) within four local populations of Zingiber zerumbet within the microgeographic area. ( $U$ and $L$ represent the $95 \%$ two-tailed confidence interval, which was calculated based on 999 permutations; a-d-local populations DS1, DS2, MLH and HJC)

(subpopulations) at microgeographic scales (metapopulations) of fully clonal or selfing plant species, any mutation that arises in local populations (subpopulations) may be fixed and cannot spread to other local populations (subpopulations). This is confirmed by the lowest proportion of common loci and the higher proportion of low-medium loci at the microgeographic level in clonal $Z$. zerumbet $(12.32 \%$ vs $27.46 \%)$ and selfing $Z$. corallinum (6.8\% vs $43.2 \%$ ) [44]. Compared to selfing plant species, obligatory clonal plant species should become more heterozygous for a particular allele in an individual small population fragment because of the absence of a capacity for sexual reproduction, thus resulting in a higher heterozygosity. Furthermore, independent ramets can prove advantageous to reduce the likelihood of the death of a genet, and consequently protecting against loss of genetic variation $[3,17]$. This was confirmed by our results, in which the proportion of common loci within local populations of clonal $Z$. zerumbet was marginally lower than that of selfing $Z$. corallinum ( $47.34 \%$ vs $67.62 \%, p=0.079$ ) and comparable to that of outcrossing $Z$. nudicarpum (47.34\% vs $37.73 \%, p=0.187)$. Moreover, $53.33 \%-$ $100 \%$ of the sampled individuals within local populations of $Z$. zerumbet were unique, which may suggest that individuals have diverged with regard to genotypic composition. This may be attributed to random genetic mutations resulting from single-base changes or transposon activation, leading to the accumulation of somaclonal variation in clonal propagation [20, $34,37,52,53$. Thus, the fully clonal plant $Z$. zerumbet may increase genetic variation within populations by the accumulation of random somatic mutations, as found in some cloned plants [3, 26, 34, 54]. Numerous studies have also shown that per-generation mutation rates in plants that reproduce vegetatively are generally expected to be higher than non-clonal plants as result of a growing number of somatic mutations $[2,55,56]$. In addition, clonal plants can be specialized for varying environmental conditions [10, 56, 57]. Habitats with contrasting environments have long been known to promote the co-existence of locally adapted genotypes through diversifying selection $[17,57,58]$, thus resulting in high levels of genetic diversity $[17,27]$. In this case, ecological differences between local populations at the microgeographic scale may also have contributed to the maintenance of genetic diversity of $Z$. zerumbet. The population-specific bands detected in every local population of $Z$. zerumbet at the microgeographic scale also imply that local populations may diverge due to different environmental conditions.

Based on the above, we suggest that conservation strategies for the genetic diversity of clonal plants, like those for selfing species, should be focused on the protection of 
all habitat types, especially isolated fragments within ecosystems, while maintenance of large populations is a key to enhancing genetic diversity for outcrossing species.

\section{Are the differences in the population genetic structure of Zingiber species at microgeographic scales related to mode of reproduction?}

Compared to outcrossing species, fully clonal plants, like selfing plants, theoretically have lower genetic diversity within populations and higher differentiation between populations [59, 60], since pollen migration between populations is rare or absent in clonal and selfing plants, and a specific locus arising in an individual population cannot spread to other populations [35, 61]. However, the genetic differentiation between local populations (subpopulations) of clonal $Z$. zerumbet was significantly lower than that of selfing $Z$. corallinum (Gst $=0.4008$ vs $0.7110, p=0.00)$ and higher than that of outcrossing $Z$. nudicarpum (Gst $=0.4008$ vs $0.3408, p=0.486$ ) in this study. AMOVA analysis also showed that more variation was found within local populations of clonal $Z$. zerumbet (54.0\%) and outcrossing $Z$. nudicarpum (53.2\%) at microgeographic scales, but the opposite was true for selfing $Z$. corallinum (21.6\%). Unlike outcrossing $Z$. nudicarpum, clonal $Z$. zerumbet obviously cannot counter genetic differentiation between local populations through gene flow [62], due to absence of migration of pollen and seeds within /among local populations at the microgeographic scale. However, prolonged clonal growth may buffer the effect of genetic drift, leading to reducing genetic differentiation between populations, as a result of the persistence of clonal propagation $[9,18]$. This is the case for clonal Z. zerumbet in our study. Furthermore, there is no inbreeding depression that could lead to increasing genetic differentiation among populations in fully clonal plants. Thus, we suggest that the fully clonal plants may have higher genetic diversity within populations and lower differentiation among populations compared to selfing plants, similar to that of outcrossing plants, albeit as a result of different strategies.

Compared with outcrossing species, selfing species always tend to show a stronger spatial genetic structure, due to lack of gene flow via pollen $[63,64]$, which is evidenced by the result of comparison between selfing $Z$. corallinum and outcrossing $Z$. nudicarpum [44]. High levels of clonal clustering are always present in plants that reproduce by vegetative propagation, due to limited dispersal ability $[2,8,65,66]$, which is confirmed by the results of our cluster analysis, showing that neighboring individuals within local populations of clonal Z. zerumbet always cluster together at the microgeographic scale, similar to selfing $Z$. corallinum (Additional file 1: Figs. S2, S3) [44]. However, many individuals do not aggregate with their neighbors within subpopulations (local populations) in outcrossing Z. nudicarpum (Additional file 1: Figs. S4, S5) [44]. Moreover, there is an absence of migration of pollen and seeds within /among local populations of fully clonal plants. Thus, fully clonal plants should generate a stronger spatial genetic structure than plants employing sexual reproduction [2,65]. Our result is consistent with this hypothesis, as evidenced by the significant positive spatial genetic structure at a smaller spatial scale $(2-14 \mathrm{~m})$ compared with selfing $Z$. corallinum (2-34 m) and outcrossing $Z$. nudicarpum (500$1500 \mathrm{~m}$ ) [44]. For clonal Z. zerumbet, this is the logical consequence, because the dispersal distances of vegetative propagules in $Z$. zerumbet are expected to be shorter than those of pollen and seed in sefling $Z$. corallinum and especially in outcrossing $Z$. nudicarpum.

\section{Conclusions}

In the present study, our results revealed that, contrary to theoretical predictions, fully clonal Zingiber zerumbet is able not only to maintain as high a level of within-population genetic diversity as outcrossing $Z$. nudicarpum, but can also harbor as high a level of microgeographic genetic diversity as selfing $Z$. corallinum, probably due to the accumulation of somatic mutations and absence of a capacity for sexual reproduction. There are differences in the spatial genetic structure of Zingiber populations at microgeographic scales and these are related to mode of reproduction. The present study advances our understanding of the effect of the means of reproduction used by plants on population genetic diversity and genetic structure.

\section{Methods}

\section{Study species, study sites and sample collection}

Zingiber zerumbet (L.) Smith is diploid perennial herb with hermaphrodite flowers, like selfing $Z$. corallinum and outcrossing $Z$. nudicarpum, and is widespread in moist places in forests, distributed across tropical regions such as south China, Cambodia, India, Laos, Malaysia, Myanmar, Sri Lanka, Thailand and Vietnam [39, 40]. However, during our 15 years (2005-2020) of fieldwork, no fruiting has been observed in any natural populations of $Z$. zerumbet in China, and thus it is considered to be sterile, reproducing vegetatively through rhizome elongation [67]. This can be confirmed by the absence of seed set after hand pollination $[41,42]$. In this study, we sampled all local populations within an area of ca. $3 \times 6 \mathrm{~km}^{2}$ across Dongshui Mountain (village) in Yangxi County (GDYX-21 $47^{\prime} 28^{\prime \prime} \mathrm{N}, 111^{\circ} 25^{\prime} 43^{\prime \prime} \mathrm{E}$, alt. 215-272 m) (Fig. 7), Guangdong Province, China, in order to examine the microgeographic genetic variation and genetic structure of clonal $Z$. zerumbet. The species has spatially 

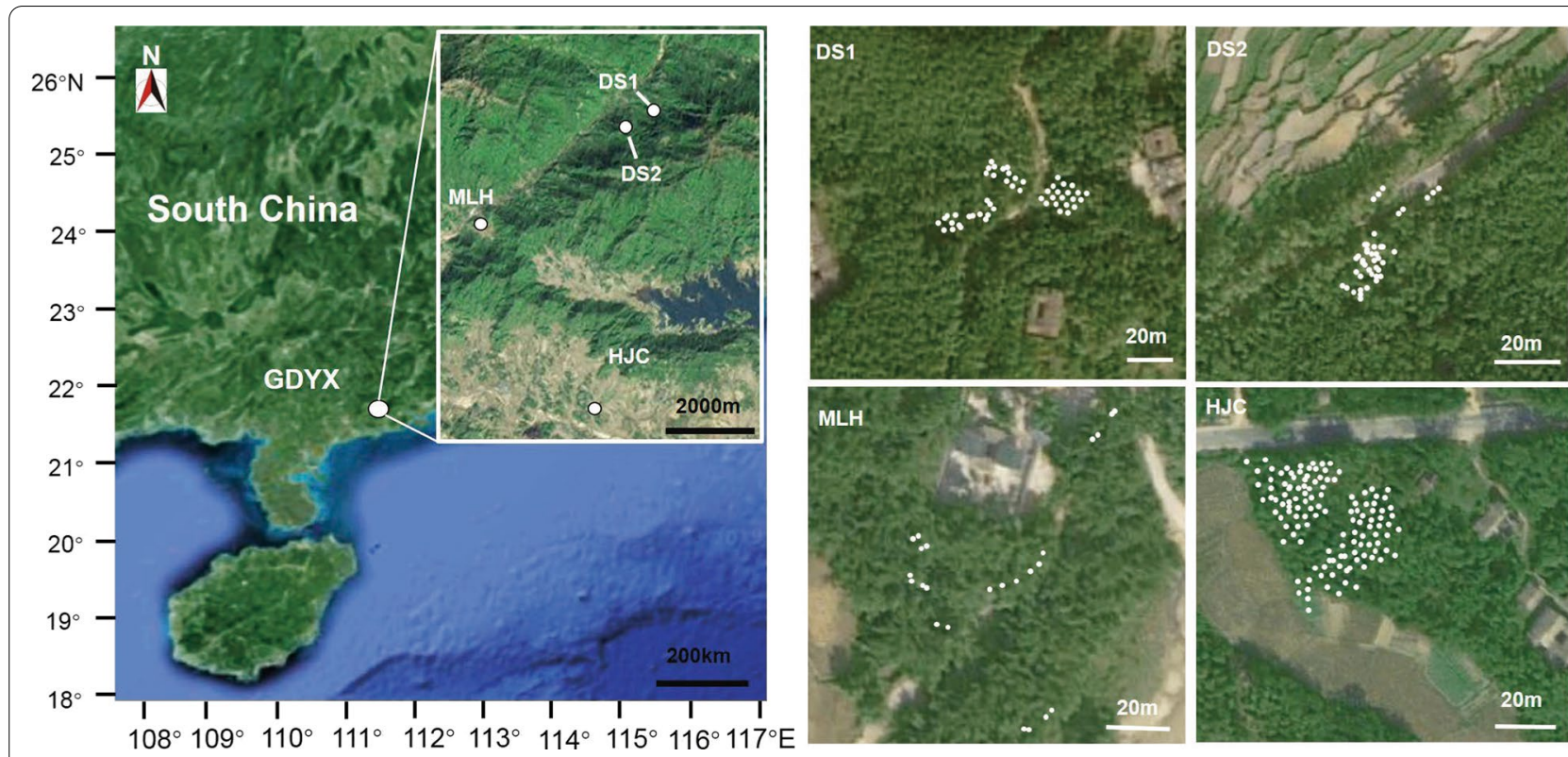

Fig. 7 Location of the microgeographic area (GDYX) and distribution of local populations of Zingiber zerumbet within GDYX. Each dot represents a sampled individual. The map was drawn by the authors with reference to Google Maps. The map can be found at https://maps.google.com/

structured populations with four local populations in different habitats naturally isolated by ca. $830-6900 \mathrm{~m}$ (average $4500 \mathrm{~m}$ ) of agricultural land, village, mountain forest, or stream. The individuals grow in open bamboo forest land near a village (HJC), on abandoned farmland (DS1) and margins of remnant forest (DS2) and alongside a stream (MLH).

In order to analyze within-population spatial genetic structure, we collected samples from 24 to 106 individuals throughout the full spatial extent of each local population (Table 2). Spatial distances between neighboring samples that appeared unconnected to each other were at least $2 \mathrm{~m}$ to minimize the risk of resampling the same clone. The straight-line distance between individuals was also estimated directly on the basis of the site coordinates to calculate the spatial autocorrelation coefficient $(r)$ within local populations. Leaf tissue samples were stored in silica gel prior to DNA analysis. Voucher specimen was collected (voucher number: wyq-14-45) for Z. zerumbet and deposited at the herbarium of South China Normal University (SN). The species was identified by professor Ying-Qiang Wang from School of Life Sciences, South China Normal University. Permissions were not necessary for collecting these samples, because they do not grow in nature reserves or included in the list of national key protected plants. Our field works and molecular experiments complied with local legislation, national and international guidelines. We also abide by the Convention on the Trade in Endangered Species of Wild Fauna and Flora.

\section{DNA extraction and PCR}

Total genomic DNA from the sampled leaves was extracted using a modified CTAB method [68]. The quality and quantity of DNA were assessed using $0.8 \%$ agarose gel electrophoresis and a spectrophotometer. ISSR-PCR amplifications were performed on a BIORAD T100 thermal cycler with an initial denaturation for 5 min at $95^{\circ} \mathrm{C}$, followed by 39 cycles of denaturation for $45 \mathrm{~s}$ at $94{ }^{\circ} \mathrm{C}$, annealing for $45 \mathrm{~s}$ and extension for $90 \mathrm{~s}$ at $72{ }^{\circ} \mathrm{C}$, with a final extension for $10 \mathrm{~min}$ at $72{ }^{\circ} \mathrm{C}$. Ten primers that have been used previously in $Z$. corallinum and $Z$. nudicarpum [43, 44] were used for $Z$. zerumbet, together with an additional two primers for this species (Table 1). PCR was carried out in a total volume of $20 \mu \mathrm{L}$, including $40 \mathrm{ng}$ template DNA, $2.0 \mu \mathrm{L} 10 \times$ buffer, $1.50 \mathrm{mmol} \mathrm{Mg}{ }^{2+}$, $0.15 \mathrm{mmol}$ dNTPs, $0.8 \mu \mathrm{mol}$ primer, 2.0 units of Taq DNA polymerase and double-distilled water. To test for possible contamination, negative controls, in which template DNA was replaced with distilled water, were included in each PCR set. The amplification products were subjected to electrophoresis on $1.8 \%$ agarose gels in $0.5 \times$ TBE buffer at $130 \mathrm{~V}$ for $1-1.5 \mathrm{~h}$ along with a 100 bp ladder, and photographed using a gel documentation system (Bio-Rad GelDoc $\mathrm{XR}^{+}$). To ensure repeatability of the results, duplicate PCR amplifications were performed and only clear and reproducible bands were scored and used in the final analysis. The images of the gels were analyzed using Image Lab software (Bio-Rad) to score for the presence (1) or absence (0) of bands and to assign a fragment size to each band using an algorithm 
based on the $100 \mathrm{bp}$ ladder. The presence or absence of bands was further confirmed by eye. A binary matrix of the ISSR phenotypes was built based on the presence or absence of bands. The binary matrix of the ISSR phenotypes was stored in the figShare repository (https://doi. org/10.6084/m9.figshare.14593941).

\section{Data analysis \\ Analysis of genetic diversity, clonal diversity, differentiation and gene flow}

The binary matrix was used to calculate the genetic diversity parameters at local population and microgeographic level using POPGENE v. 1.32 [69]. These parameters were as follows: percentage of polymorphic loci $(P P L)$, observed number of alleles $(\mathrm{Na})$, effective number of alleles $(\mathrm{Ne})$, Nei's gene diversity $(h)$, and Shannon's information index $(I)$. Samples with similarities above 0.98 were considered to be identical and to belong to the same genotype [70]. Two measures of clonal diversity for each local population were used in our study as follows: (1) The "proportion distinguishable" ( $G / N$ ratio), which was defined as the number of genotypes $(G)$ divided by the number of samples $(N)$ [16]; (2) Simpson's diversity index $(D)$, which was defined as $1-\sum\left[n_{i}\left(n_{i}-1\right) / \mathrm{N}(\mathrm{N}-\right.$ $1)$ ], where $n_{i}$ is the number of samples of genotype $i$ and $\mathrm{N}$ is the total number of samples collected for that local population [71]. $G_{\mathrm{ST}}$, an indicator of the degree of differentiation between local populations, was calculated using POPGENE. To assess the values of population genetic differentiation $(\Phi)$ and the proportion of total variation among and within local populations, the matrix was also subjected to an analysis of molecular variance (AMOVA) implemented in GenAlEx 6.502 [72] based on 999 permutations. Gene flow $(\mathrm{Nm})$ between local populations was calculated as $N \mathrm{~m}=0.5\left(1-G_{\mathrm{ST}}\right) / G_{\mathrm{ST}}[73]$.

\section{Analysis of genetic structure}

STRUCTURE v. 2.1 [74] was used to derive the number of genetic units and to assign an individual to $\mathrm{K}$ genetic clusters. We performed five runs for each value of $\mathrm{k}$, with a run length of 1,000,000 Markov chain Monte Carlo (MCMC) replications after a burn-in period of 100,000. In order to illustrate the genetic relationship between individuals, a dendrogram was constructed using an unweighted paired group method with an arithmetic average analysis (UPGMA) based on the Dice coefficient in NTSYSpc-2.10 [75]. A neighbor-joining (NJ) tree was also generated in MEGA v. 7 [76] from the genetic distances matrix [77]. Principal Coordinates Analysis (PCoA) using GenAlEx provided a visual representation of the genetic relationships within and between local populations of $Z$. zerumbet. Mantel tests implemented in GenAlEx were performed to examine whether genetic distances between local populations were related to the corresponding measures of geographic distance.

\section{Spatial genetic structure (SGS) within local populations}

To investigate genetic relatedness of individuals with respect to spatial position within local populations, single population spatial structure analyses were performed to assess the spatial genetic structure of the studied local populations using GenAlEx. To reduce noisy confidence limits in case of uneven sampling, even sample classes were chosen [72]. The autocorrelation coefficient $(r) \mathrm{cal}-$ culated according to Smouse and Peakall [78] is similar to Moran's- $I$, ranging from -1 to 1 . To test the statistical significance of the spatial autocorrelation values, a classic two-tailed $95 \%$ confidence interval (CI) was generated and bootstrap resampling was performed 999 times.

\section{Abbreviations}

$G$ : Number of genotypes; $S$ : Number of genotypes found only once; $G / N$ : The number of genotypes (G) relative to that of samples (N); D: Simpson's diversity index; PL: Number of polymorphic loci; PPL: Percentage of polymorphic loci; Na: Number of observed alleles; Ne: Number of effective alleles; $h$ : Nei's gene diversity; l: Shannon's information index; NS: Number of specific bands; Tm: Annealing temperature; SR: Size range of amplified fragments; NT: Total number of bands; NP: Number of polymorphic bands; $H_{T}$ :Total microgeographic diversity; $H_{s}$ : Average within local population diversity; $G_{S T}$ : Local population differentiation; $N \mathrm{Nm}$ : Gene flow; df: Degrees of freedom; $\boldsymbol{\Phi}_{\mathrm{ST}}$ : Between local populations deviations from Hardy-Weinberg expectations; $p$ : The probability of accepting the null hypothesis.

\section{Supplementary Information}

The online version contains supplementary material available at https://doi. org/10.1186/s12862-021-01853-2.

Additional file 1: Fig S1-S5. Fig. S1. Inflorescence of Zingiber zerumbet, Z. nudicarpum and Z. corallinum. Fig. S2. UPGMA dendrogram based on Dice coefficient for individuals in metapopulations of Zingiber corallinum (A-GDZJ, B-GDYX). The figure utilized in this study is from Huang et al. [44]. Fig. S3. Unrooted Neighbor-Joining trees based on Nei's genetic distance for individuals in metapopulations of Zingiber corallinum (A-GDZJ, $B-G D Y X)$. The figure utilized in this study is from Huang et al. [44]. Fig. S4. UPGMA dendrogram based on Dice coefficient for individuals in metapopulations of Zingiber nudicarpum (A-HNCJ, B-HNBT). The figure utilized in this study is from Huang et al. [44]. Fig. S5. Unrooted Neighbor-Joining trees based on Nei's genetic distance for individuals in metapopulations of Zingiber nudicarpum (A-HNCJ, B-HNBT). The figure utilized in this study is from Huang et al. [44].

\section{Acknowledgements}

Not applicable.

\section{Authors' contributions}

YQW designed the study, collected field samples, analyzed all data and wrote the manuscript; RH collected field samples, assisted with the molecular experiments, analyzed data and wrote the manuscript; YW collected field samples, conducted the molecular experiments and analyzed data; $\mathrm{KL}$ assisted with the molecular experiments. All authors read and approved the final manuscript. 


\section{Funding}

This work was funded by the Joint Fund of the National Natural Science Foundation of China and Guangdong Provincial Government (no. U1301213), the National Natural Science Foundation of China (No. 30770376) and the key project of the Natural Science Foundation of Guangdong Province of China (No. 7117864)

\section{Availability of data and materials}

The binary matrix of the ISSR phenotypes is available in the figShare repository (https://doi.org/10.6084/m9.figshare.14593941). The map in Fig. 7 is available on https://maps.google.com/.

\section{Declarations}

\section{Ethics approval and consent to participate}

Not applicable.

\section{Consent for publication}

Not applicable.

\section{Competing interests}

The authors declare that they have no competing interests.

\section{Author details}

${ }^{1}$ Guangzhou Key Laboratory of Subtropical Biodiversity and Biomonitoring, School of Life Sciences, South China Normal University, Guangzhou 510631, China. ${ }^{2}$ Guangdong Provincial Key Laboratory of Biotechnology for Plant Development, School of Life Sciences, South China Normal University, Guangzhou 510631, China.

Received: 26 January 2021 Accepted: 27 May 2021

Published online: 09 June 2021

\section{References}

1. Holsinger KE. Reproductive systems and evolution in vascular plants. Proc Natl Acad Sci USA. 2000:97:7037-42.

2. Vallejo-Marín M, Dorken ME, Barrett SCH. The ecological and evolutionary consequences of clonality for plant mating. Annu Rev Ecol Evol S. 2010;41:193-213.

3. Barrett $\mathrm{SCH}$. Influences of clonality on plant sexual reproduction. Proc Natl Acad Sci USA. 2015;112:8859-66.

4. Eckert CG. The loss of sex in clonal plants. Evol Ecol. 2002:15:501-20.

5. Chung MY, Suh Y, López-Pujol J, Nason JD, Chung MG. Clonal and finescale genetic structure in populations of a restricted Korean endemic, Hosta jonesii (Liliaceae) and the Implications for Conservation. Ann Bot. 2005;96:279-88.

6. Honnay O, Jacquemyn $\mathrm{H}$. Clonal plants: beyond the patterns-ecological and evolutionary dynamics of asexual reproduction. Evoly Ecol. 2010:24:1393-7.

7. Alberto F, Gouveia L, Arnaud-Haond S, Pérez-Lloréns JL, Duarte CM, Serrão EA. Within-population spatial genetic structure, neighbourhood size and clonal subrange in the seagrass Cymodocea nodosa. Mol Ecol. 2005:14:2669-81.

8. Mizuki I, Ishida K, Tani N, Tsumura Y. Fine-scale spatial structure of genets and sexes in the dioecious plant Dioscorea japonica, which disperses by both bulbils and seeds. Evol Ecol. 2010;24:1399-415.

9. Binks RM, Millar MA, Byrne M. Contrasting patterns of clonality and fine-scale genetic structure in two rare sedges with differing geographic distributions. Heredity. 2015;115:235-42.

10. Jacquemyn $H$, Brys $R$, Honnay $O$, Hermy M, Roldán-Ruiz I. Sexual reproduction, clonal diversity and genetic differentiation in patchily distributed populations of the temperate forest herb Paris quadrifolia (Trilliaceae). Oecologia. 2006;147:434-44

11. Diggle PK, Lower S, Ranker TA. Clonal diversity in alpine populations of Polygonum viviparum (Polygonaceae). Int J Plant Sci. 1998;15:606-15.

12. Honnay $O$, Bossuyt $B$. Prolonged clonal growth: escape route or route to extinction? Oikos. 2005;108:427-32.
13. O'Brien EK, Denham AJ, Ayre DJ. Patterns of genotypic diversity suggest a long history of clonality and population isolation in the Australian arid zone shrub Acacia carneorum. Plant Ecol. 2014:215:55-71.

14. Vandepitte K, Roldán-Ruiz I, Jacquemyn H, Honnay O. Extremely low genotypic diversity and sexual reproduction in isolated populations of the self-incompatible lily-of-the-valley (Convallaria majalis) and the role of the local forest environment. Ann Bot. 2010;105:769-76.

15. Wang MZ, Li HL, Li JM, Yu FH. Correlations between genetic, epigenetic and phenotypic variation of an introduced clonal herb. Heredity. 2020;124:146-55

16. Ellstrand NC, Roose ML. Patterns of genotypic diversity in clonal plant species. Am J Bot. 1987;74:123-31.

17. Widén B, Cronberg N, Widén M. Genotypic diversity, molecular markers and spatial distribution of genets in clonal plants, a literature survey. Folia Geobot. 1994;29:245-63.

18. Honnay $\mathrm{O}$, Jacquemyn H, Roldán-Ruiz I, Hermy M. Consequences of prolonged clonal growth on local and regional genetic structure and fruiting success of the forest perennial Maianthemum bifolium. Oikos. 2006;112:21-30.

19. Honnay $\mathrm{O}$, Jacquemyn $\mathrm{H}$. A meta-analysis of the relation between mating system, growth form and genotypic diversity in clonal plant species. Evol Ecol. 2008;22:299-312.

20. Wibowo A, Becker C, Durr J, Price J, Spaepen S, Hilton S, Putra H, Papareddy R, Saintain Q, Harvey S, Bending GD, Schulze-Lefert P, Weigel D, Gutierrez-Marcos G. Partial maintenance of organ-specific epigenetic marks during plant asexual reproduction leads to heritable phenotypic variation. Proc Natl Acad Sci USA. 2018;115:E9145-52.

21. Bartlewicz J, Vandepitte K, Jacquemyn H, Honnay O. Population genetic diversity of the clonal self-incompatible herbaceous plant Linaria vulgaris along an urbanization gradient. Biol J Linn Soc. 2015;116:603-13.

22. Godoy FMDR, Lenzi M, Ferreira BHS, Silva LV, Zanella CM, Paggi GM. High genetic diversity and moderate genetic structure in the selfincompatible, clonal Bromelia hieronymi (Bromeliaceae). Biol J Linn Soc. 2018;187:672-88.

23. Kudoh H, Shibaike H, Takasu H, Whigham D, Kawano S. Genet structure and determinants of clonal structure in a temperate deciduous woodland herb Uvularia perfoliata. J Ecol. 1999:87:244-57.

24. Stehlik I, Holderegger R. Spatial genetic structure and clonal diversity of Anemone nemorosa in late successional deciduous woodlands of Central Europe. J Ecol. 2000;88:424-35.

25. Brzosko E, Wróblewska A, Ratkiewicz M. Spatial genetic structure and clonal diversity of island populations of lady's slipper (Cypripedium calceolus) from the Biebrza National Park (northeast Poland). Mol Ecol. 2002;11:2499-509.

26. Balloux F, Lehmann L, de Meeûs T. The population genetics of clonal and partially clonal diploids. Genetics. 2003;164:1635-44.

27. Richards CL, Hamrick JL, Donovan LA, Mauricio R. Unexpectedly high clonal diversity of two salt marsh perennials across a severe environmental gradient. Ecol Lett. 2004;7:1155-62.

28. de Witte LC, Armbruster GJ, Gielly L, Taberlet P, Stöcklin J. AFLP markers reveal high clonal diversity and extreme longevity in four key arctic alpine species. Mol Ecol. 2012;21:1081-97.

29. Brzosko E, Wróblewska A, Jermakowicz E, Hermaniuk A. High level of genetic variation within clonal orchid Goodyera repens. Plant Syst Evol. 2013:299:1537-48.

30. Loh R, Scarano FR, Alves-Ferreira M, Salgueiro F. Clonality strongly affects the spatial genetic structure of the nurse species Aechmea nudicaulis (L.) Griseb. (Bromeliaceae). Bot J Linn Soc 2015:178·329-41.

31. Williams CF, Ruvinsky J, Scott PE, Hews DK. Pollination, breeding system, and genetic structure in two sympatric Delphinium (Ranunculaceae) species. Am J Bot. 2001;88:1623-33.

32. Aizen MA, Ashworth L, Galetto L. Reproductive success in fragmented habitats: do compatibility systems and pollination specialization matter? J Veg Sci. 2002:13:885-92.

33. Charlesworth D. Effects of inbreeding on the genetic diversity of populations. Philos T R Soc B. 2003;358:45.

34. Meloni M, Reid A, Caujapé-Castells J, Marrero Á, Fernández-Palacios JM, Mesa-Coelo RA. Effects of clonality on the genetic variability of rare, insular species: the case of Ruta microcarpa from the Canary Islands. Ecol Evol. 20013;3:1569-79. 
35. Ingvarsson PK. A metapopulation perspective on genetic diversity and differentiation in partially self-fertilizing plants. Evolution. 2002;56:2368-73.

36. Pettengill JB, Runquist RDB, Runquist DA. Mating system divergence affects the distribution of sequence diversity within and among populations of recently diverged subspecies of Clarkia xantiana (Onagraceae). Am J Bot. 2016;103:99-109.

37. Fischer M, van Kleunen M. On the evolution of clonal plant life histories. Evol Ecol. 2002;15:565-82

38. Mazer JS. Alternative approaches to the analysis of comparative data compare and contrast. Am J Bot. 1998;85:1194-9.

39. Wu TL. Zingiber. In: Wu ZY, editor. Flora Reipublicae Popularis Sinicae. Beijing: Science Press; 1981. p. 139-49.

40. Wu TL, Larsen K. Zingiberaceae. In: Wu ZY, Peter HR, editors. Flora of China. Beijing: Science Press, and St. Louis: Missouri Botanical Garden Press; 2000. p. 322-77.

41. Wu WH. 2008. Studies on breeding systems of two species in Zingiber (Zingiberaceae). Master's Thesis, South China Normal University, Guangzhou.

42. Tan B. 2010. Studies on pollination biology in Zingiber (Zingiberaceae). Master's Thesis, South China Normal University, Guangzhou.

43. Huang R, Chu QH, Lu GH, Wang YQ. Comparative studies on population genetic structure of two closely related selfing and outcrossing Zingiber species in Hainan Island. Sci Rep. 2019;9:1-11.

44. Huang R, Zhang ZD, Wang Y, Wang YQ. Genetic variation and genetic structure within metapopulations of two closely related selfing and outcrossing Zingiber species (Zingiberaceae). AoB Plants. 2021;13:1-15.

45. Govindaraj $M$, Vetriventhan $M$, Srinivasan M. Importance of genetic diversity assessment in crop plants and its recent advances: an overview of its analytical perspectives. Genet Res Int. 2015; 2015:431487.

46. Yan J, Zhu MD, Liu W, Xu Q, Zhu CY, Li JQ, Sang T. Genetic variation and bidirectional gene flow in the riparian plant Miscanthus lutarioriparius, across its endemic range: implications for adaptive potential. GCB Bioenergy. 2016;8:764-76

47. Picó FX, Van Groenendael J. Large-scale plant conservation in European semi-natural grass-lands: a population genetic perspective. Divers Distrib. 2007;13:920-6.

48. Mijangos JL, Pacioni C, Spencer PBS, Craig MD. Contribution of genetics to ecological restoration. Mol Ecol. 2015;24:22-37.

49. Tsyusko OV, Smith MH, Sharitz RR, Glenn TC. Genetic and clonal diversity of two cattail species, Typha latifolia and T. angustifolia (Typhaceae), from Ukraine. Am J Bot. 2005:92:1161-9.

50. Pfeiffer T, Klahr A, Heinrich A, Schnittler M. Does sex make a difference? Genetic diversity and spatial genetic structure in two co-occurring species of Gagea (Liliaceae) with contrasting reproductive strategies. Plant Syst Evol. 2011;292:189-201.

51. Honnay $\mathrm{O}$, Jacquemyn $\mathrm{H}$. Susceptibility of common and rare plant species to the genetic consequences of habitat fragmentation. Conserv Biol. 2007;21:823-31.

52. Lushai G, Loxdale HD, Maclean N. Genetic diversity in clonal lineages. J Reprod Develop. 2000;46:21-2.

53. Orive ME. Somatic mutations in organisms with complex life histories. Theor Popul Biol. 2001:59:235-49.

54. Kreher SA, Foré SA, Collins BS. Genetic variation within and among patches of the clonal species Vaccinium stamineum. L Mol Ecol. 2000;9:1247-52.

55. Salomonson A. Interactions between somatic mutations and plant development. Vegetatio. 1996;127:71-5.

56. Douhovnikoff V, Dodd RS. Epigenetics: a potential mechanism for clonal plant success. Plant Ecol. 2015:216:227-33.
57. Lenssen JPM, van Kleunen A, Fischer M, de Kroon H. Local adaptation of the clonal plant Blackwell Publishing, Ltd. Ranunculus reptans to flooding along a small-scale gradient. J Ecol. 2004;92:696-706.

58. Prati D, Schmid B. Genetic differentiation of life-history traits within populations of the clonal plant Ranunculus reptans. Oikos. 2000;90:442-56.

59. Hamrick JL, Godt MJW. Effects of life history traits on genetic diversity in plant species. Philos T R Soc B. 1996:351:1291-8.

60. Reisch C, Bernhardt-Römermann M. The impact of study design and life history traits on genetic variation of plants determined with AFLPs. Plant Ecol. 2014;215:1493-511.

61. Pannell JR, Charlesworth B. Effects of metapopulation processes on measures of genetic diversity. Philos TR Soc B. 2000;355:1851-64.

62. Ohhayashi K, Hodoki Y, Kondo NI, Kunii H, Shimada M. A massive tsunami promoted gene flow and increased genetic diversity in a near threatened plant species. Sci Rep. 2017;7:10933.

63. Vekemans $X$, Hardy OJ. New insights from fine-scale spatial genetic structure analyses in plant populations. Mol Ecol. 2004;13:921-35.

64. Duminil J, Hardy OJ, Petit RJ. Plant traits correlated with generation time directly affect inbreeding depression and mating system and indirectly genetic structure. BMC Evol Biol. 2009;9:177-90.

65. Jacquemyn H, Brys R, Honnay O, Hermy M, Roldán-Ruiz I. Local forest environment largely affects below-ground growth, clonal diversity and fine-scale spatial genetic structure in the temperate deciduous forest herb Paris quadrifolia. Mol Ecol. 2005;14:4479-88.

66. Ohsako T. Clonal and spatial genetic structure within populations of a coastal plant, Carex kobomugi (Cyperaceae). Am J Bot. 2010;97:458-70.

67. Kavitha PG, Thomas G. Population genetic structure of the clonal plant Zingiber zerumbet (L.) Smith (Zingiberaceae), a wild relative of cultivated ginger, and its response to Pythium aphanidermatum. Euphytica. 2008;160:89-100

68. Doyle JJ, Doyle JL. A rapid DNA isolation procedure for small quantities of fresh leaf material. Phytochem Bull. 1987;19:11-5.

69. Yeh FC, Yang RC, Boyle TBJ, Ye ZH, Mao JX, Yeh C, Timothy B, Mao X: Popgene, the user friendly shareware for population genetic analysis. http:// www.ualberta.ca/ fyeh/index.htm (2000). Accessed Dec 2000.

70. Arens P, Grashof-Bokdam CG, van der Sluis T, Smulders MJM. Clonal diversity and genetic differentiation of Maianthemum bifolium among forest fragments of different age. Plant Ecol. 2005;179:169-80.

71. Pielou EC. An introduction to mathematical ecology. New York: WileyInterscience; 1969.

72. Peakall R, Smouse PE. GenAlEx 6.5: genetic analysis in Excel. Population genetic software for teaching and research--an update. Bioinformatics. 2012;28:2537-39

73. McDermott JM, McDonald BA. Gene flow in plant pathosystems. Annu Rev Phytopathol. 1993;31:353-73.

74. Pritchard JK, Stephens MJ, Donnelly PJ. Inference of population structure using multilocus genotype data. Genetics. 2000;155:945-59.

75. Rohlf FJ: NTSYS-pc, version 2.10. http://www.sputtr.com/ntsyspc.2000. Accessed Dec 2000.

76. Kumar S, Stecher G, Tamura K. MEGA7: molecular evolutionary genetics analysis version 7.0 for bigger datasets. Mol Biol Evol. 2016;33:1870-4.

77. Nei M, LiWH. Mathematical model for studying genetic variation in terms of restriction endonucleases. Proc Natl Acad Sci USA. 1979:76:5269.

78. Smouse PE, Peakall R. Spatial autocorrelation analysis of individual multiallele and multilocus genetic structure. Heredity. 1999;82:561-73.

\section{Publisher's Note}

Springer Nature remains neutral with regard to jurisdictional claims in published maps and institutional affiliations. 